$13{ }^{\text {A COMPARISON OF SERUM ENZYMES IN VENOUS AND ARTERIAL }}$ 1338 CORD BLOOD AT BIRTH. Marvin Leventer, Mehmet Y. Dincsoy, Soo Jae Kim, Foazia Siddiq (Sponsored by P.J. Collipp) Health Sclences Center, SunY at Stony Brook, Nassau County Medical Center, Department of Pediatrics, East Meadow, NX.

Serum enzymes in the human fetus may originate from mother, placenta or the fetus. We studied paired samples of umbilical cord artery (A) and venous (V) serum enzyme activities, namely, creatine phosphokinase (CPK), lactate dehydrogenase (LDH), aspartate aminotransferase (AST), amylase and alkaline phosphatase (A1k-P). The study group consisted of a total of $30 \mathrm{in-}$ tase (Alk-P). The study group consisted of a total of 30 intional age of $38.6 \pm 2.4 \mathrm{wks}$. The following is a comparison between venous and arterial serum levels of the remaining enzymes

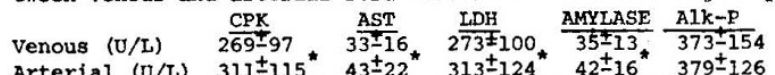

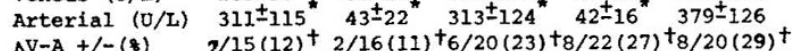
$\frac{\Delta V-A+/-(8) \quad 2 / 15(12)^{+} 2 / 16(11)+6 / 20(23)+8 / 22(27)+8 / 20(29) t}{\text { Paired } t: ~ * p<0.05 ; ~ w i l c o x o n ~ s i g n e d ~ r a n k ~ t e s t: ~ t p<0.05 ~}$ Serum CPK, IDH and amylase were higher in the serum of A than $V$ Serum CPK, LDH and amylase were higher in the serum of A than $V$
and the direction of changes were significantly upward from $V$ to and the direction $\mathrm{V}$ changes were signifeantly upward from represents fetal contribution and/or placental uptake during each passage of feto-placental circulatory cycle. Intrapartum fetal and placental disorders are expected to produce more acute changes which may be instrumental for further understanding of this issue. Supported in part by grant MOD-226.
1341

EFFECTIVENESS OF EARLY ARGININE (ARG) THERAPY IN ARGININOSUCCINIC ACIDURIA (ASA). Steven M. Donn and Jess G. Thoene, Dept. of Pediatrics, University of Michigan Hospitals, Ann Arbor, ML

The effectiveness of ARG therapy in preventing neonatal hyperammonemia is illustrated by the outcomes of two preterm siblings with ASA. The first case was referred at 4 days of age with lethargy, apnea, coma, and a plasma ammonia concentration of $1992 \mu \mathrm{g} / \mathrm{dl}$. She received hemodialysis, lowering ammonia to $133 \mu \mathrm{g} / \mathrm{dl}$, but a rapid rebound to $843 \mu \mathrm{g} / \mathrm{dl}$ prompted institution of ARG therapy, $4 \mathrm{mM} / \mathrm{kg} / \mathrm{d}$ as $5 \% \mathrm{ARG}-\mathrm{HCl}$. This lowered ammonia to normal concentrations for the remainder of the hospitalization, at a plasma ARG concentration of $360 \mu \mathrm{M}$. At 20 months she is profoundly retarded, cannot sit or stand, and functions at a 3 month level. The second case was diagnosed antenatally by the presence of ASA in amniotic fluid. A male child delivered at 32 weeks, began receiving ARG therapy at 32 hours of age when the plasma ammonia had increased to $196 \mu \mathrm{gg} / \mathrm{dl}$. ARG, at the same dose, produced a plasma ARG concentration of $184 \mu \mathrm{M}$ and successfully prevented hyperammonemia. At four months of age his neurologic examination is normal and his development is age-appropriate. Both children have been maintained on a protein-restricted diet Both children have been maintained on a protein-restricted diet supplemented with
$\mathrm{mM} / \mathrm{kg} / \mathrm{d}$ of each.

Treatment of inborn errors of the urea cycle has advanced greatly in the past decade with the advent of alternative means of waste nitrogen disposal. Early diagnosis and treatment of ASA with ARG appears to be a highly effective therapy of an otherwise severe and of ten lethal inborn error of metabolism.

\section{BLOOD GLUCOSE (BG) CONCENTRATIONS AND CRANIAL ULTRA- SOUND (US) ABNORMALITIES IN LOW BIRTH WEIGHT (LBW)} INFANTS. Mehmet Y. Dincsoy, Foazia Siddig, Marvin Leventer, Kathleen McKeever, Susan Tuck. (Spon. by Platon J. Collipp). Health Sciences Center, SUNY at Stony Brook, Nassau County Medical Center, Department of Pediatrics, East Meadow, NY.
Hyperglycemia by producing hyperosmolar state and hypoglyceHyperglycemia by producing hyperosmolar state and hypogly
mia by an induction of catecholamine release both have been mia by an induction of catecholamine release both have been
claimed to play a role in the causation of subependymal-intraventricular hemorrhage (SE-IVH). Theoretically, it is expected that BG levels within the first day of life will have an influence on the incidence of SE-IVH in LBW infants. We studied the relationship between SE-TVH and BG in $58 \mathrm{LBW}$ infants $(\leq 2000 \mathrm{gm})$ by US study of the head routinely at least once within the first 5 days of life. The mean, highest and lowest BG levels were determined during the first 24 hours of life. The Infants studied had a birth weight (meantSD) of $1475 \pm 561 \mathrm{gm}, 1$ and 5 minutes Apgar scores of $5.4 \pm 2.3$ and $7.2 \pm 2.1$ respectively. The following is the comparison of the infants with normal and abnormal cranial US as they relate to BG status during the first 24 hours of life: \begin{tabular}{llllllll} 
& \multicolumn{3}{c}{ Blood Glucose (mg/di) } & Highest BG & Lowest BG \\
Groups & Mean & Highest & Lowest & $>125 / \leq 125$ & $\leq 30 />30 \mathrm{mg} / \mathrm{dI}$ \\
\hline Abnormal US & $76 \pm 17$ & $112 \pm 26$ & $44 \pm 16$ & $7 / 16$ & $(30 *) * 5 / 18$ & $(228)$
\end{tabular} \begin{tabular}{lllllll} 
Aonormal US & $76 \pm 17$ & $112 \pm 26$ & $44 \pm 16$ & $7 / 16$ & $(307) * 5 / 18$ & $(228)$ \\
Normal US $69 \pm 20$ & $109 \pm 30$ & $45 \pm 15$ & $6 / 29$ & $(178) * 6 / 29$ & (178) \\
\hline
\end{tabular} $\mathrm{x}^{2}=2.61, \mathrm{p}=\mathrm{ns}$

since there is no significant difference between the groups with regard to glucose homeostasis, the effect of abnormal BG concentrations on the incidence of SE-IVH seems to be absent or questionable and needs to be analyzed in a larger sample.

\section{USE OF DEXAMETHASONE (DXM) IN SEVERE}

1340 NEONATAL RESPIRATORY DISEASE SECONDARY TO Roger G. Faix and Steven M. Donn, Dept. of Pediatrics, Univ. of Michigan, Ann Arbor, MI. (Spon. by G.W. Goldstein).

Eight newborn infants, gestational ages $32-42$ wks (mean $37 \pm 3.6$ ) and birthweights 1870-4160 gms (mean 2899 \pm 687 ) were treated with DXM, $1.0 \mathrm{mg} / \mathrm{kg}$ IV every $12 \mathrm{hrs}$ for 4 doses for severe respiratory disease secondary to PPHN. All were receiving IPPV and could not be weaned below an $\mathrm{FiO}_{2}$ of $0.65 ; 7$ of 8 were receiving $\mathrm{FiO}_{2}>0.85$. Mean age at DXM therapy was 9.8 days (range 6-17) and mean prior duration of $\mathrm{FiO}_{2} 1.0$ was 123 hrs (range 56-189). Parameters monitored before, during, and after therapy included mean airway pressure (PAW), ventilator rate (IMV), $\mathrm{FiO}_{2}$, and alveolar-arterial oxygen gradient ( $\mathrm{A}-$ a $\mathrm{DO}_{2}$ ). Changes in these parameters from initiation to completion of therapy were:

$$
\begin{aligned}
& \text { mean } \pm \text { SD } \frac{\triangle \mathrm{PAW}}{3.6 \pm 2.1} \quad \frac{\triangle \mathrm{IMV}}{14.4 \pm 9.2} \quad \frac{\triangle \mathrm{FiO}_{2}}{0.30 \pm 0.13} \quad \frac{\triangle \mathrm{A}-\mathrm{a} \mathrm{DO}_{2}}{221 \pm 77}
\end{aligned}
$$

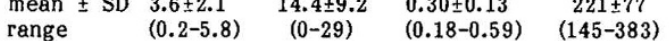

The mean time until $\mathrm{FiO}_{2}$ could be reduced to $<0.5$ was $60.7 \mathrm{hrs}$ (range 33-123). The mean time until IMV could be halved was 84.9 hrs (range 28-150). All infants were receiving systemic antibiotics when therapy began; no significant new infections occurred. Transient elevations in serum sodium (2), blood pressure (2), and serum glucose (2) were noted but were not clinically significant.

Our observations suggest DXM is beneficial in the treatment of severe respiratory disease in newborns requiring intensive ventilatory management beyond 5 days of age. A controlled clinical trial will be necessary to demonstrate long-term safety and efficacy.
1342 MORBIDITY AND MORTALITY OF MULTIFETAL 1342 GESTATION LESS THAN 1500 GRAMS. Steven M. Donn
and Rose M. Viscardi (Spon. by G.w. Golddstein), Dept. of Pediatrics, University of Michigan Hospitals, Ann Arbor, ML.

The clinical courses and outcomes of 61 twins and 9 triplets with birthweights less than 1500 grams (multifetal group, MFG) and delivered at Women's Hospital between Jan. 1980 and June 1983 were compared to all 174 inborn singletons less than 1500 grams (singleton group, SG) delivered during the same interval.

MFG infants were significantly smaller (birthweights $976 \pm 277 \mathrm{~g}$ v. $1111 \pm 238$ g for $\mathrm{SG}, \mathrm{p}<0.001$ ) and more premature (gestational ages was $\overrightarrow{39} \%$, compared to only $17 \%$ in the SG, p $<0.001$.

Analysis of obstetric factors between MFG and SG showed premature onset of labor ( $p<0.001$ ) and cesarean section (CS) following labor ( $p$ $<0.001)$ to be more common in the MFG, while CS without labor was more common in the $S G(p=0.002)$.

The incidence of respiratory distress (RD), $\mathrm{XPPV}$ and $\mathrm{FiO}_{2}>0.4$, was higher in the MFG $(83 \%)$ than in the SG $(69 \%), \mathrm{p}<0.05$. The overall incidence and severity of intraventricular hemorrhage (IVH) was similar in both groups, though factors associated with IVH differed. Among the MFG, IVH was more commonly seen only in infants with RD. For the SG, IVH was more common with birthweight $<1000 \mathrm{~g}(\mathrm{p}=0.02), 5$ minute Apgar $<5 \quad(p<0.03)$, RD $(p<0.0001)$, and death $(p<0.0001)$. Postnatal phenobarbital therapy reduced the incidence of IVH in the SG from $37 \%$ to $17 \%$, but had no apparent effect in the MFG.

We conclude that MFG infants tend to be more premature and smaller than SG infants, and have an increased risk of mortality which does not appear related to IVH.

PREDICTIVE FEATURES OF MORTALITY AND MORBIDITY DUE TO 1343 GROUP B STREPTOCOCCAL (GBS) MENINGITIS, Morven S. College of Medicine, Department of Pediatrics, Houston.

Clinical and laboratory features at admission for GBS meningitis have not been assessed as possible predictors of mortality or major neurological sequelae. From 1974 through 1979, 61 patients were admitted with this diagnosis. Infection was rapidly fatal in $13(21 \%)$ and 38 of $48(79 \%)$ survivors were evaluated at a mean of 5.8 years later (range 3.3 to 8.9 ). Of these 51 infants, 21 of 5.8 years later (range 3.3 to 8.9 ). Of these 51 infants, 21 $30(59 \%)$ were normal or had minor residuae. Analysis of admission parameters revealed a significant risk of death or major morbidity in patients who had coma or semicoma, decreased peripheral perfusion, total $\mathrm{WBC}<5,000 / \mathrm{mm}^{3}$, absolute $\mathrm{PMN}<1,000 / \mathrm{mm}^{3}$, serum $\mathrm{HCO}_{3}<15$ $\mathrm{mg} / \mathrm{dl}$ and CSF protein $>300 \mathrm{mg} / \mathrm{dl}$ ( $p \leq 0.03, x^{2}$ analysis). Features $\mathrm{mt}$ sionistion. tio of immature to total $P M N \geq 0.2, W B C<100 / \mathrm{mm}^{3}$ in $\mathrm{CSF}$, CSF gram tio of immature to total PMN $\geq 0.2$, WBC $<100 / \mathrm{mm}^{3}$ in CSF, CSF gram
stain, and CSF glucose $<10 \mathrm{mg} / \mathrm{dl}$. Among the 14 infants with earstain, and CSF glucose $<10 \mathrm{mg} / \mathrm{dl}$. Among the 14 infants with ear-
ly-onset meningitis, the mean birth weight of 5 with a fatal outcome $(2.056 \mathrm{~kg})$ was significantly less than that of 9 survivors $(3.277 \mathrm{~kg}),(\mathrm{t}=3.3, p<0.01)$. The serious morbidity and mortality declined from $80 \%$ (1974) to $25 \%$ (1979). Application of these data may allow the prospective identification of patients at high risk for major sequelae associated with GBS meningitis. Furthermore, cautious optimism may be communicated to parents when infants do not have features predictive of major morbidity. 